Heavy-ion-induced modification of structural and mechanical properties of carbon-nanotube aerogels

S. Charnvanichborikarn, S. J. Shin, M. A. Worsley, S. O. Kucheyev

November 26, 2012

Carbon 
This document was prepared as an account of work sponsored by an agency of the United States government. Neither the United States government nor Lawrence Livermore National Security, LLC, nor any of their employees makes any warranty, expressed or implied, or assumes any legal liability or responsibility for the accuracy, completeness, or usefulness of any information, apparatus, product, or process disclosed, or represents that its use would not infringe privately owned rights. Reference herein to any specific commercial product, process, or service by trade name, trademark, manufacturer, or otherwise does not necessarily constitute or imply its endorsement, recommendation, or favoring by the United States government or Lawrence Livermore National Security, LLC. The views and opinions of authors expressed herein do not necessarily state or reflect those of the United States government or Lawrence Livermore National Security, LLC, and shall not be used for advertising or product endorsement purposes. 


\title{
Heavy-ion-induced modification of structural and mechanical properties of carbon-nanotube aerogels
}

\author{
S. Charnvanichborikarn, M. A. Worsley, S. J. Shin, and S. O. Kucheyev \\ Lawrence Livermore National Laboratory, Livermore, California 94550, USA
}

(Dated: October 17, 2012)

\begin{abstract}
We study the effect of $2 \mathrm{MeV} \mathrm{Xe}{ }^{+}$ion bombardment at room temperature on the microstructure and mechanical properties of cross-linked carbon-nanotube-based nanoporous carbons. Irradiation causes a gradual densification and a decrease in the surface roughness of monoliths, an increase in Young's modulus and failure stress, a decrease in the failure strain, and smoothening of nanoligament surfaces. Our results demonstrate a potential of heavy-ion bombardment for a controlled modification of nanoporous carbons.
\end{abstract}

\section{INTRODUCTION}

Monolithic nanoporous carbons have high electrical and thermal conductivities, large surface areas, and a tunable morphology. ${ }^{1}$ Such remarkable properties and potentially low material costs make this class of materials attractive for a number of energy-related applications. The most common method to synthesize monolithic nanoporous carbons is the traditional sol-gel wet-chemistry approach. It involves polymerization of a resorcinol-formaldehyde solution followed by a pyrolysis converting a polymeric gel into a graphitic carbon network. ${ }^{1,2}$ Materials thus prepared are also known as carbon aerogels (CAs) and xerogels.

Numerous efforts have recently been made to synthesize novel carbon nanotube (CNT) and graphene based foams with improved properties compared to those of conventional CAs. ${ }^{3-11}$ For example, Worsley et al. ${ }^{5,11}$ have demonstrated composites of CNTs and conventional CAs (which we will refer to as "CNT-CAs") with a three dimensional network of CNT bundles decorated and cross-linked by graphitic carbon nanoparticles. As compared to conventional CAs, such CNT-CAs have enhanced mechanical stiffness and electrical conductivity ${ }^{5,11}$

Properties of nanofoams can be tuned for specific applications by post-synthesis processing. Of particular interest are processing steps that improve nanofoam mechanical properties. Indeed, low-density nanoporous carbons possess poor mechanical properties, limiting many applications. $^{11-14}$ This problem is common to all highporosity/low-density solids and is related to a superlinear dependence of mechanical properties on the monolith density. ${ }^{11-15}$

Irradiation with particle beams can be used for a controlled post-synthesis modification of material properties. $^{16}$ Numerous previous studies have been dedicated to understanding particle radiation effects in carbon nanostructures and, in particular, in individual CNTs and their non-cross-linked assemblies. ${ }^{17}$ In contrast, little is known about the radiation response of more complex macroassemblies of cross-linked CNTs such as CNT-CAs. We have recently reported a study of the electrical resistance of CNT-CAs irradiated with ions of $\mathrm{MeV}$ energies with different masses $\left({ }^{1} \mathrm{H},{ }^{4} \mathrm{He},{ }^{20} \mathrm{Ne},{ }^{40} \mathrm{Ar}\right.$, and $\left.{ }^{129} \mathrm{Xe}\right) .{ }^{18} \mathrm{In}$ all the cases studied, ion bombardment has been found to cause an initial increase in the electrical resistance. This process is controlled by nuclear energy loss of ions. For ${ }^{20} \mathrm{Ne}$ and heavier ions, irradiation above certain critical fluences leads to a reduction in the electrical resistance, which we have attributed to the process of ion-beam-induced foam densification. ${ }^{18}$ Hence, heavy-ion irradiation could be used to control not only the electrical properties of CNT-CAs but also the monolith density and, likely, mechanical properties that, as mentioned above, are of particular interest for low-density nanoporous solids.

Stimulated by such recent observations, ${ }^{18}$ here, we study structural and mechanical properties of CNT-CAs bombarded at room temperature with energetic heavy ions $\left(2 \mathrm{MeV}{ }^{129} \mathrm{Xe}\right)$. We find that heavy-ion irradiation causes dramatic changes in CNT-CAs, including a gradual densification of monoliths, an increase in Young's modulus and failure stress, a decrease in the failure strain, smoothening of nanoligament surfaces, and a decrease in the surface roughness of monoliths.

\section{EXPERIMENTAL}

The CNT-CAs studied here were synthesized as described in detail elsewhere. ${ }^{5}$ In brief, purified single-walled CNTs (Carbon Solutions, Inc.) were dispersed in water by sonication. Sol-gel precursors (resorcinol and formaldehyde) and the polymerization catalyst $\left(\mathrm{NaCO}_{3}\right)$ were added, and the mixture gelled. Wet gels were washed with acetone, dried with supercritical $\mathrm{CO}_{2}$, and pyrolyzed at $1050{ }^{\circ} \mathrm{C}$ under $\mathrm{N}_{2}$. Pyrolyzed monoliths, with a density of $\sim 30 \mathrm{mg} \mathrm{cm}^{-3}$ and a CNT loading of $\sim 50$ wt. $\%$, were machined with a 6-mm-diameter cylindrical endmill rotating at a speed of $2 \times 10^{4}$ revolutions per minute, yielding macroscopically flat surfaces $\left(\sim 1 \times 1 \mathrm{~cm}^{2}\right.$ in size $)$ needed for ion irradiation and mechanical characterization by indentation.

Irradiation was carried out at room temperature with 2 $\mathrm{MeV}{ }^{129} \mathrm{Xe}^{+}$ions with a beam flux of $10^{12} \mathrm{~cm}^{-2} \mathrm{~s}^{-1}$ to various ion fluences with the $4 \mathrm{MV}$ ion accelerator (National Electrostatics Corporation, model $4 \mathrm{UH}$ ) at Lawrence Livermore National Laboratory. During irradiation, a portion of each specimen was shadowed from the ion beam by an Al sheet. A projected range of $2 \mathrm{MeV}$ Xe ions in CNT-CAs $(\sim 45 \mu \mathrm{m})$ was calculated with the TRIM code (version SRIM-2011.08) ${ }^{19}$ with threshold displacement and lattice binding energies of 28 and $3 \mathrm{eV}$, respectively. ${ }^{20,21}$

After irradiation, samples were indented in the load- 
controlled mode in an MTS XP nanoindenter with a flat punch diamond tip with an effective diameter of $62 \mu \mathrm{m}$. A series of partial indents with multiple load-unload cycles (with complete unloading) were performed. Representative indentation stress $(\sigma)$ and strain $(\varepsilon)$ were defined as $\sigma_{\text {punch }}=$ $4 P /\left(\pi D^{2}\right)$ (i.e., the average contact pressure) and $\varepsilon_{\text {punch }}=$ $4 h /(\pi D) \approx h / D$ (i.e., the proportionality coefficient between $\sigma_{\text {punch }}$ and the reduced modulus in the elastic regime). ${ }^{12,22}$ Here, $P$ is the load, $D$ is the flat punch indenter tip diameter, and $h$ is the indenter displacement. Both loading and unloading rates were kept constant to maintain an indentation strain rate of $10^{-3} \mathrm{~s}^{-1} \cdot{ }^{12}$ Young's modulus $(E)$ was calculated based on the initial slope of the unloading curve according to the Oliver-Pharr method ${ }^{23}$ for maximum loads below those resulting in the failure (pop-in) events discussed below.

Samples were also indented with a spherical sapphire indenter with a radius of $496 \mu \mathrm{m}$ to a maximum load of 500 $\mathrm{mN}$. Such indentations have left circular Hertzian cracks on monolith surfaces. ${ }^{24}$ The crack radius $\left(R_{\text {crack }}\right)$, measured by optical microscopy, could be correlated with representative spherical indentation strain at which cracks form: $\varepsilon_{\text {sphere }}^{\mathrm{f}}=$ $\left(4 R_{\text {crack }}\right) /\left(3 \pi R_{\text {ind }}\right)$, where $R_{\text {ind }}$ is the radius of the spherical indenter. ${ }^{12}$ Assumptions of such an analysis include (i) a frictionless contact and (ii) that Hertzian cracks form at the contact radius. Note that $\varepsilon_{\text {sphere }}^{\mathrm{f}}$ should be considered as a useful fracture parameter (that scales linearly with $\left.R_{\text {crack }}\right),{ }^{25}$ without any implicit correlation of such $\varepsilon_{\text {sphere }}^{\mathrm{f}}$ with components of the strain tensor distributions under the indenter tip. Indeed, the Hertzian analysis is valid only in the regime of small elastic deformations, while the CNTCAs studied here develop Hertzian cracks for contact radii comparable or even larger than the radius of the indenter.

The step height at the border between unirradiated (masked during bombardment) and irradiated areas of the surface was measured by optical microscopy and/or by operating the nanoindenter as a profilometer with the flat punch tip acting as a stylus probe. Selected samples were examined by scanning electron microscopy (SEM) in a JEOL 7401-F microscope operated at $2 \mathrm{kV}$ and by bright-field transmission electron microscopy (TEM) in a FEI TF-20 Tecnai microscope operated at $200 \mathrm{kV}$.

\section{RESULTS AND DISCUSSION}

In this section, we present experimental results and discuss how Xe-ion irradiation modifies different properties and the microstructure of CNT-CAs.

\section{A. Elasticity}

Figure 1 shows load-displacement curves of CNT-CAs before and after irradiation with $2 \mathrm{MeV} \mathrm{Xe}$ ions to various fluences. Indentation stress and strain axes are also shown in Fig. 1. ${ }^{22}$ In all the cases of Figs. 1(a) - 1(f), loading is characterized by an initial elastic region when the monolith shape is restored after the stress is removed. The

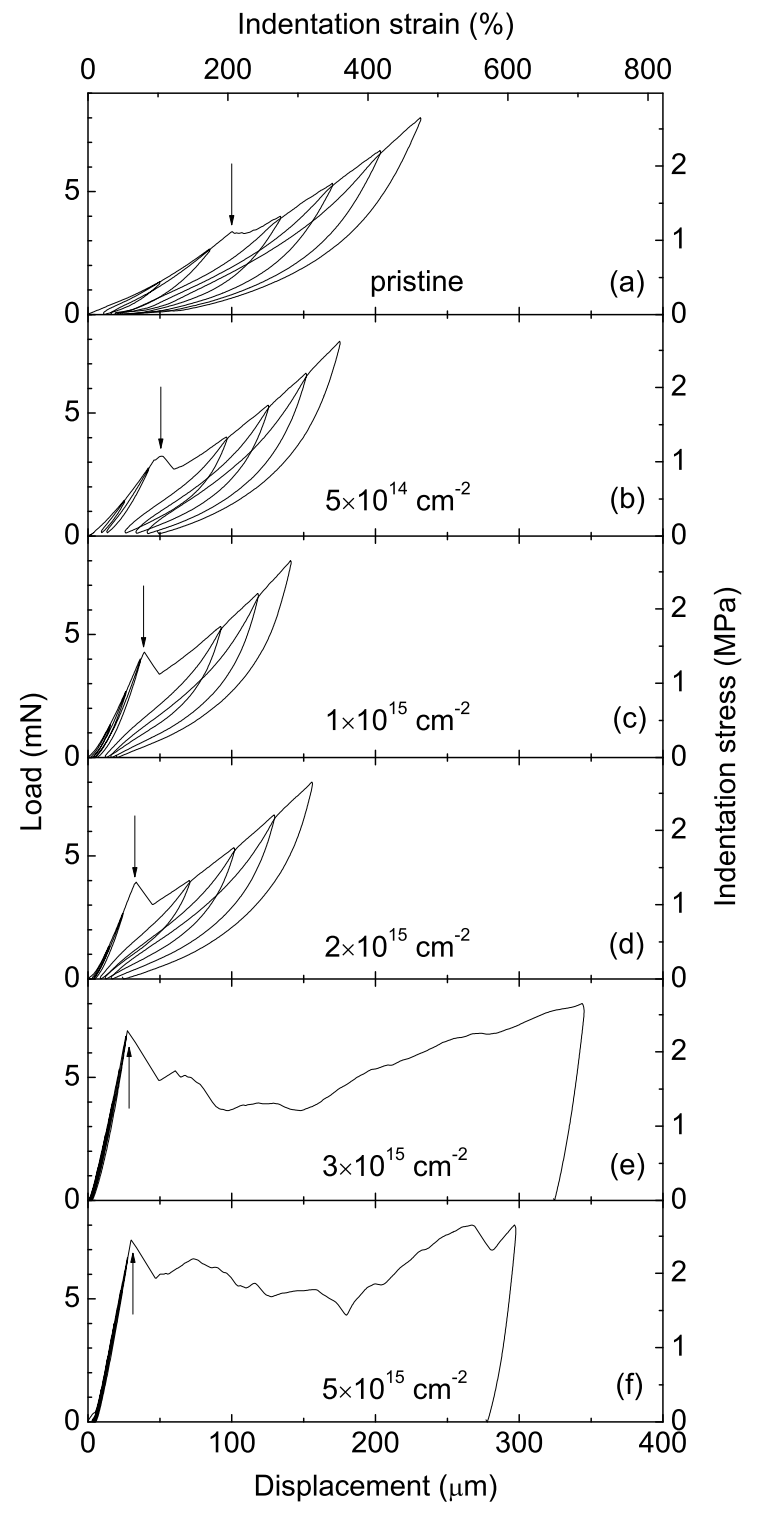

FIG. 1: Representative load-displacement (stress-strain) curves of (a) unirradiated and (b)-(f) 2-MeV-Xe-ion-irradiated CNT-CAs. Irradiation fluences are indicated in the legends. Irradiation was performed at room temperature. Indentation was done with a flat punch tip with a diameter of $62 \mu \mathrm{m}$ as a series of loading cycles with increasing maximum loads and complete unloading at the end of each load cycle. The maximum load was $8 \mathrm{mN}$ in all the cases. Arrows denote the first pop-in events.

evolution of the elastic modulus under irradiation is shown in Fig. 2(a), revealing that $E$ monotonically increases with fluence. Such an increase in $E$ is in contrast to a number of previous observations of a radiation-induced decrease in $E$ for individual CNTs, attributed to defect production. ${ }^{26-29}$ This apparent inconsistency could be reconciled by noting that, in addition to the properties of the material forming aerogel nanoligaments (i.e., CNT bundles decorated and cross-linked by graphitic nanoparticles in the the case of CNT-CAs), mechanical properties of aerogels are determined 


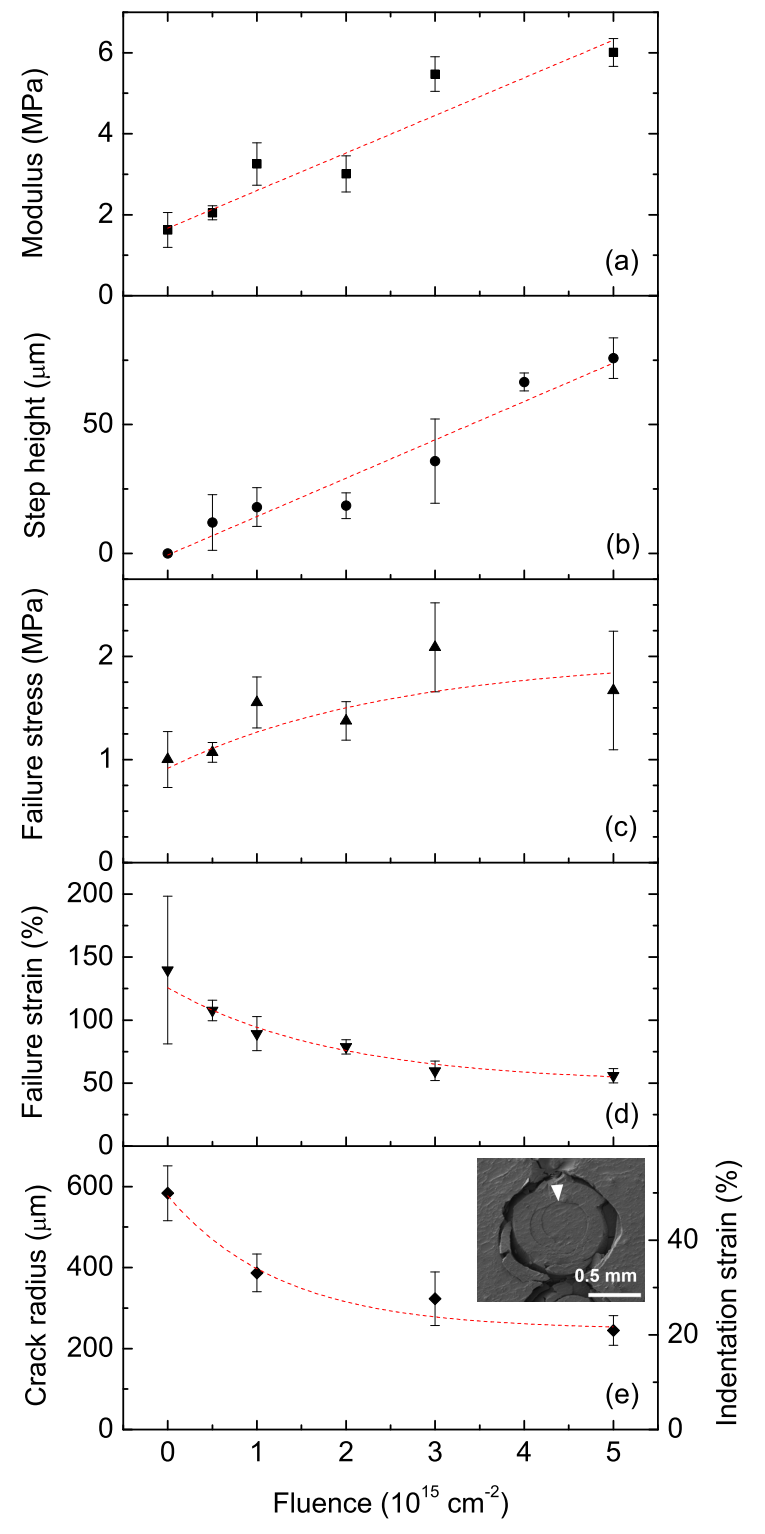

FIG. 2: (Color online) Ion fluence dependencies of (a) Young's modulus, (b) the step height between irradiated and unirradiated regions of the monolith surface, (c) failure stress, (d) failure strain, and (e) the Hertzian crack radius (the left scale) and corresponding spherical indentation strain (the right scale) of CNT-CAs irradiated at room temperature with $2 \mathrm{MeV}$ Xe ions. Error bars represent one standard deviation. Dash lines are to guide reader's eye. Data shown in (a), (c), and (d) are measured with flat punch indentation. The inset in (e) is a SEM image illustrating typical ring cracks (with the smallest one denoted with an arrowhead) on a sample bombarded with $\mathrm{Xe}$ ions to a fluence of $5 \times 10^{15} \mathrm{~cm}^{-2}$ and indented with a spherical tip to a load of $500 \mathrm{mN}$.

by the monolith density as well as by the geometry, size, and network connectivity of nanoligaments. ${ }^{11-15,25}$ The irradiation-induced improvement in $E$ revealed by Figs. 1 and 2(a) could be related to the formation of new crosslinks between adjacent ligaments as a result of irradiation. ${ }^{30}$ However, as discussed below, we attribute it largely to
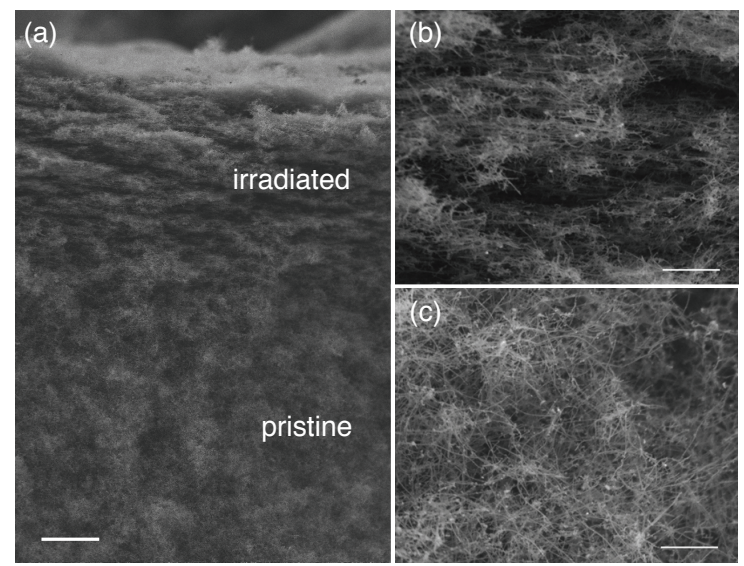

FIG. 3: (a) Low-magnification cross-sectional SEM image showing near-surface densification of CNT-CAs caused by $2 \mathrm{MeV}$ Xe ion irradiation to a fluence of $3.5 \times 10^{15} \mathrm{~cm}^{-2}$. Higher magnification cross-sectional SEM images from near-surface regions of pristine and irradiated CNT-CAs are shown in (b) and (c), respectively. The scale bars are $10 \mu \mathrm{m}$ in (a) and $1 \mu \mathrm{m}$ in (b) and (c).

radiation-induced changes in the monolith density.

\section{B. Densification}

Heavy-ion-induced densification of CNT-CAs is clearly visible in the cross-sectional SEM image of Fig. 3(a), revealing an $\sim 30 \mu \mathrm{m}$ thick densified near-surface layer in a monolith irradiated to a fluence of $3.5 \times 10^{15} \mathrm{~cm}^{-2}$. Figures 3(b) and and 3(c) further illustrate densification effects by showing higher magnification cross-sectional SEM images of CNT-CAs before and after irradiation, respectively. Figure 2(b) shows the ion fluence dependence of the step height between irradiated and unirradiated regions of the monolith surface. It is seen from Fig. 2(b) that the structure of nanoporous carbon compacts almost linearly with Xeirradiation fluence.

Zawislak and coworkers, ${ }^{31}$ have reported anomalously large sputtering yields of fullerene $\left(\mathrm{C}_{60}\right)$ films irradiated with $25 \mathrm{keV} \mathrm{Xe}$ ions to very low fluences of $\lesssim 10^{12} \mathrm{~cm}^{-2}$. However, in the present case of CNT-CAs bombarded with $2 \mathrm{MeV} \mathrm{Xe}$ ions, the appearance of a step between irradiated and unirradiated regions is evidence of ion-beam-induced material densification rather than possibly anomalously large sputtering or erosion processes. We have verified it by Rutherford backscattering spectrometry (RBS) measurements of the areal density of $\mathrm{C}$ atoms in CNT-CAs before and after Xe ion irradiation. In such RBS experiments, performed with $2 \mathrm{MeV}{ }^{4} \mathrm{He}$ ions, an $\sim 150-\mu \mathrm{m}$-thick CNT-CA film with a density of $\sim 30 \mathrm{mg} \mathrm{cm}^{-3}$ (corresponding to $\sim 2.4 \times 10^{19} \mathrm{C}$ atoms $\mathrm{cm}^{-2}$ ) was placed on a Au substrate, and the carbon areal thickness was monitored by the energy shift of the $\mathrm{Au}$ surface edge. 


\section{Failure stress and strain}

Along loading branches in Fig. 1 beyond the elastic regime, material failure appears as a sudden jump of the strain at a constant stress. These are so called "pop-in" events, denoted by arrows in Fig. 1. Interestingly, for all irradiated samples, pop-in events occur at depths from the sample surface close to the $R_{\mathrm{p}}$ of $2 \mathrm{MeV}$ Xe ions $(\sim 45 \mu \mathrm{m})$ as well as the thickness of the densified layer shown in Fig. $3(\sim 30 \mu \mathrm{m})$. We assign the stress and strain at the initial stage of the first pop-in event as the failure stress $\left(\sigma_{\text {punch }}^{\mathrm{f}}\right)$ and strain $\left(\varepsilon_{\text {punch }}^{\mathrm{f}}\right)$, respectively. It can be seen from Fig. 1, and more clearly from Figs. 2(c) and $2(d)$, that $\sigma_{\text {punch }}^{\mathrm{f}}$ gradually increases while $\varepsilon_{\text {punch }}^{\mathrm{f}}$ decreases with increasing Xe ion fluence. Radiation-induced changes to $\sigma_{\text {punch }}^{\mathrm{f}}$ and $\varepsilon_{\text {punch }}^{\mathrm{f}}$ are substantial - a factor of 2 for the maximum fluence of Fig. 2 compared to corresponding values for unirradiated CNT-CAs.

Effective failure strains could also be estimated from observations of Hertzian surface cracks formed by spherical indentation. $^{25}$ Shown in the inset in Fig. 2(e) is a SEM image illustrating typical Hertzian ring cracks on a sample bombarded with Xe ions to a fluence of $5 \times 10^{15} \mathrm{~cm}^{-2}$ and then indented with a spherical tip (with a radius of $496 \mu \mathrm{m}$ ) to a maximum load of $500 \mathrm{mN}$. Multiple rings are evidence of indentation beyond the critical load for crack formation. Figure 2(e) shows the dependence of the Hertzian crack radius (the left scale) and corresponding indentation strain $\varepsilon_{\text {sphere }}^{\mathrm{f}}$ (the right scale) on fluence of $2 \mathrm{MeV}$ Xe ions. It illustrates that unirradiated CNT-CAs have a very large elastic range and can sustain spherical indentation strains $\varepsilon_{\text {sphere }}^{\mathrm{f}} \sim 50 \%$ without fracture. In fact, for unirradiated samples, the Hertzian crack radius is larger than the radius of the indenter tip. It is also seen from Fig. 2(e) that the representative Hertizan fracture strain and crack radius decrease with increasing ion fluence. The curves of Figs. 2(d) and 2(e) are qualitatively similar, supporting the assumption that both $\varepsilon_{\text {punch }}^{\mathrm{f}}$ and $\varepsilon_{\text {sphere }}^{\mathrm{f}}$ are representative failure strains.

\section{Surface roughness of monoliths and morphology of nanoligaments}

Figure 4 illustrates the surface morphology of CNTCA monoliths before [Fig. 4(a)] and after [Figs. 4(b)4(d)] irradiation with increasing $\mathrm{Xe}$ ion fluence. It is seen from Fig. 4(a) that, at the microscale, the surface of an unirradiated monolith planarized by machining with an endmill exhibits a wavy pattern. Bombardment with Xe ions results in smoothening the monolith surface [Figs. 4(b)-4(d)]. Such an irradiation-induced surface smoothening process could be understood in terms of sputtering and redeposition of nanoligaments. ${ }^{18}$ The same physical phenomena could also explain ion-beam-induced smoothening of the surface of individual nanoligaments, qualitatively revealed by a comparison of TEM images from Figs. 5(a) and 5(b). Also seen from Fig. 5 is radiation-induced amorphization of ligaments in irradiated CNT-CAs. Such amorphization is consistent with a number of previous observations. ${ }^{17,18}$
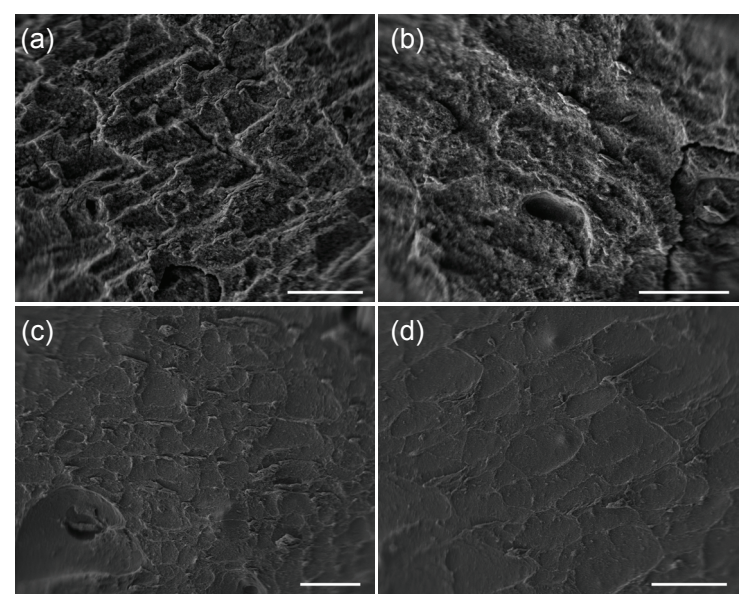

FIG. 4: Representative SEM images showing the surface morphology of CNT-CAs before (a) and after bombardment with 2 $\mathrm{MeV}$ Xe ions to fluences of (b) $1 \times 10^{15}$, (c) $3 \times 10^{15}$, and (d) $5 \times 10^{15}$ $\mathrm{cm}^{-2}$. All the scale bars are $100 \mu \mathrm{m}$.

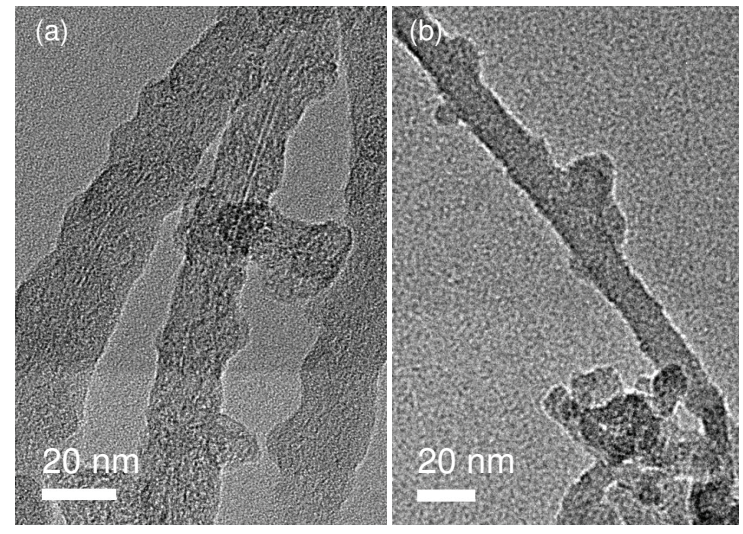

FIG. 5: TEM images of CNT-CAs showing nanoligaments before (a) and after (b) irradiation at room temperature with $2 \mathrm{MeV}$ Xe ions to a fluence of $7 \times 10^{15} \mathrm{~cm}^{-2}$.

\section{SUMMARY OF HEAVY-ION-INDUCED MODIFICATION OF CARBON AEROGELS}

In conclusion, we have demonstrated the potential of heavy-ion bombardment for controlled modification of nanoporous carbons. In particular, we have found that irradiation of CNT-CAs with $2 \mathrm{MeV} \mathrm{Xe}$ ions at room temperature causes (i) an increase in Young's modulus [Fig. 2(a)] and failure stress [Fig. 2(c)], a decrease in the failure strain [Figs. 2(d) and 2(e)], foam densification [Figs. 2(b) and 3], smoothening of both the monolith surface [Fig. 4] and surfaces of nanoligaments [Fig. 5], and amorphization of CNTs [Fig. 5]. Hence, heavy-ion irradiation could, for example, be used for the formation of multilayer nanoporous structures with variable stiffness and failure parameters, with the layer thickness controlled by ion energy. These multilayer structures could be attractive for minimizing contact and wear damage in energy absorbing structures $^{3}$ and compliant electrical contacts. ${ }^{32}$ 


\section{ACKNOWLEDGMENTS}

This work was performed under the auspices of the U.S. DOE by LLNL under Contract DE-AC52-07NA27344.
Transmission electron microscopy experiments were conducted at the National Center for Electron Microscopy, LBNL, which is supported by the U.S. DOE under Contract DE-AC02-05CH11231.
1 See, for example, a recent review by A. M. Elkhatat and S. A. Al-Muhtaseb, Adv. Mater. 23, 2887 (2011).

2 R. W. Pekala, J. Mater. Sci. 24, 3221 (1989).

3 A. Cao, P. L. Dickrell, W. G. Sawyer, M. N. Ghasemi-Nejhad, and P. M. Ajayan, Science 310, 1307 (2005).

4 M. B. Bryning, D. E. Milkie, M. F. Islam, L. A. Hough, J. M. Kikkawa, and A. G. Yodh, Adv. Mater. 19, 661 (2007)

5 M. A. Worsley, S. O. Kucheyev, J. H. Satcher, A. V. Hamza, and T. F. Baumann, Appl. Phys. Lett. 94, 073115 (2009).

6 M. Xu, D. N. Futaba, T. Yamada, M. Yumura, and K. Hata, Science 330, 1364 (2010).

7 X. Gui, J. Wei, K. Wang, A. Cao, H. Zhu, Y. Jia, Q. Shu, and D. Wu, Adv. Mater. 22, 617 (2010).

8 R. R. Kohlmeyer, M. Lor, J. Deng, H. Liu, and J. Chen, Carbon 49, 2352 (2011).

9 Z. Chen, W. Ren, L. Gao, B. Liu, S. Pei, and H.-M. Cheng, Nat. Mater. 10, 424 (2011).

10 M. A. Worsley, S. O. Kucheyev, H. E. Mason, M. D. Merrill, B. P. Mayer, J. Lewicki, C. A. Valdez, M. E. Suss, M. Stadermann, P. J. Pauzauskie, J. H. Satcher, J. Biener, and T. F. Baumann, Chem. Commun. 48, 8428 (2012).

11 S. J. Shin, S. O. Kucheyev, M. A. Worsley, and A. V. Hamza, Carbon 50, 5340 (2012).

12 S. O. Kucheyev, A. V. Hamza, J. H. Satcher Jr., and M. A. Worsley, Acta Mater. 57, 3472 (2009).

13 J. Gross, J. Fricke, R. Pekala, and L. W. Hrubesh, Phys. Rev. B 45, 12774 (1992).

14 R. W. Pekala, C. T. Alviso, and J. D. Lemay, J. Non-Cryst. Solids 125, 67 (1990).

15 See, for example, L. J. Gibson and M. F. Ashby, Cellular Solids (Cambridge University Press, Cambridge, 1997).

16 See, for example, a review by J. S. Williams, Rep. Prog. Phys. 49 491 (1986).

17 See, for example, a review by A. V. Krasheninnikov and K. Nordlund, J. Appl. Phys. 107, 071301 (2010), and references therein.
18 S. Charnvanichborikarn, S. J. Shin, M. A. Worsley, and S. O. Kucheyev, Appl. Phys. Lett. 101, 103114 (2012).

19 J. F. Ziegler, J. P. Biersack, and U. Littmark, The Stopping and Range of Ions in Solids (Pergamon, New York, 1985), Vol. 1, p 109.

20 We note that TRIM-code calculations typically underestimate the $R_{\mathrm{p}}$ for implantation of heavy ions into light substrates. ${ }^{21}$ Hence, the actual $R_{\mathrm{p}}$ value is likely larger than $\sim 45 \mu \mathrm{m}$.

21 P. L. Grande, F. C. Zawislak, D. Fink, and M. Behar, Nucl. Instrum. Methods Phys. Res. B 61, 282 (1991).

22 For flat punch indentation, representative stress and strain are directly proportional to load and displacement, respectively.

23 W. C. Oliver and G. M. Pharr, J. Mater. Res. 7, 1564 (1992).

24 H. Hertz, J. Reine Angew. Math 92156 (1881).

25 S. O. Kucheyev, M. Stadermann, S. J. Shin, J. H. Satcher Jr., S. A. Gammon, S. A. Letts, T. van Buuren, and A. V. Hamza, Adv. Mater. 24, 776 (2012).

26 J.-P. Salvetat, J.-M. Bonard, N. H. Thomson, A. J. Kulik, L. Forró, W. Benoit, and L. Zppiroli, Appl. Phys. A 69, 255 (1999).

27 S. L. Mielke, D. Troya, S. Zhang, J.-L Li, S. Xiao, R. Car, R. S. Ruoff, G. C. Schatz, and T. Belytschko, Chem. Phys. Lett. 390, 413 (2004).

28 S. Zhang, S. L. Mielke, R. Khare, D. Troya, R. S. Ruoff, G. C. Schatz, and T. Belytschko, Phys. Rev. B 71, 115403 (2005).

29 M. Sammalkorpi, A. V. Krasheninnikov, A. Kuronen, K. Nordlund, and K. Kaski, Nucl. Instrum. Methods Phys. Res. B 228, 142 (2005).

30 See, for example, B. Peng, M. Locascio, P. Zapol, S. Li, S. L. Mielke, G. C. Schatz, and H. D. Espinosa, Nat. Nanotechnol. 3, 626 (2008).

31 F. C. Zawislak, M. Behar, D. Fink, P. L. Grande, J. A. H. da Jornada, and J. R. Kaschny, Phys. Lett. A 226, 217 (1997).

32 G. Toth, J. Malkin, N. Halonen, J. Palosaari, J. Juuti, H. Jantunen, K. Kordas, W. G. Sawyer, R. Vajtai, and P. M. Ajayan, Adv. Mater. 21, 2054 (2009). 